\title{
CURRÍCULO ESCOLAR COMO MOBILIZAÇÕES INVENTIVAS E AFETIVAS PELA PRÁTICA DOCENTE
}

\author{
Kátia Sebastiana Carvalho dos Santos Farias ${ }^{1}$ \\ Éverton Feitosa dos Santos 2 \\ Fernanda Costa de Góes 3
}

\begin{abstract}
RESUMO
O objetivo deste texto é problematizar práticas curriculares e o fazer docente com base em estudos realizados na disciplina "Inovações Curriculares e Didática", em um Programa de Pós-Graduação em Educação Escolar de uma universidade federal situada no Norte do Brasil. Tem como base teórica estudiosos do campo do currículo, como Veiga-Neto, Ivor Goodson, Marluce Paraíso e Sônia Clareto. Os diálogos ficcionais dos jogos de cenas, inspirados na terapia desconstrucionista de Jacques Derrida (1971) e nos jogos de linguagem de Ludwig Wittgenstein (1999), mostram a potência de práticas docentes curriculares a partir de formas outras que permitam re(pensar) padrões unívocos estabelecidos e consolidados na educação escolar.
\end{abstract}

Palavras-chave: Práticas docentes. Currículo escolar. Jogos de cenas. Educação escolarizada.

\section{SCHOOL CURRICULUM AS INVENTIVE AND AFFECTIVE MOBILIZATIONS FOR TEACHING PRACTICE}

\begin{abstract}
This text's goal is to problematize curricular practices and teaching practice based on studies carried out in the Curricular Innovations and Didactics subject, in the school Education Post-Graduation Program in a Federal Univeristy located in a nothern region in Brazil. It has a theoretical basis in scholars in the curriculum field with Veiga-Neto, Ivor Goodson, Marluce Paraíso and Sônia Clareto. The fictional dialogues of game scenes, inspired by Jacques Derrida's (1971) desconstructionist

\footnotetext{
${ }^{1}$ Doutora em Educação pela Universidade Estadual de Campinas (Unicamp); docente do Departamento de Matemática da Universidade Federal de Rondônia (UNIR); professora do Programa de Pós-Graduação em Educação Escolar - Mestrado e Doutorado Profissional da UNIR. Atua no grupo de pesquisa Educação, Linguagem e Práticas Culturais (PHALA Unicamp). Orcid iD: http://orcid.org/0000-0003-2564-4390. E-mail: katiafarias@unir.com

2 Aluno do Mestrado Profissional em Educação Escolar (UNIR); professor de Matemática na Escola Estadual de Ensino Fundamental e Médio Estudo e Trabalho. Orcid iD: https://orcid.org/0000-0003-3808-1451. E-mail: evertonstark20@gmail.com

3 Aluna do Mestrado Profissional em Educação Escolar (UNIR); técnica pedagoga na reitoria do Instituto Federal de Educação, Ciência e Tecnologia de Rondônia (IFRO). Orcid iD: https://orcid.org/0000-0001-7948-5300. E-mail: fernanda.goes@ifro.edu.br
} 
therapy and Ludwig Wittgenstein's (1999) language games, show the potency of curricular teaching practices from other ways that allow re(thinking) univocal patterns established and consolidated in school education.

Keywords: Teaching practices. School curriculum. Scene games. Schooled education.

\section{CURRÍCULOS ESCOLARES COMO MOVILIZACIONES INVENTIVAS Y AFECTIVAS POR LA PRÁCTICA DOCENTE}

\section{RESUMEN}

El objetivo de este texto es problematizar prácticas curriculares y el hacer docente basado en estudios realizados en la diciplina Inovações Curriculares e Didática, en un programa de Posgrado en Graduación Escolar de una Universidad Federal ubicada en el norte de Brasil. La base teórica está en académicos en el campo del currículo, como Veiga-Neto, Ivor Goodson, Marluce Paraíso y Sônnia Clareto. Los diálogos ficticios de los juegos de escenas, inspirados en la terapia deconstruccionista de Jaques Derrida (1971) y en los juegos del lenguaje de Ludwig Wittgenstein (1999), muestran la potencia de prácticas docentes curriculares a partir de otras formas que permitan re(pensar) patrones unívocos establecidos y consolidados en la educación escolar.

Palabras-claves: Prácticas docentes. Currículo escolar. Juegos de escenas. Educación escolarizada.

\section{INTRODUÇÃO}

[...] a formação não estaria ligada a processos de racionalização, conscientização e disciplinamento, mas sim a processos outros de afetação, sensibilização, rupturas, recriações, reinvenções. Assim, formar pode ser pensado como desviar, profanar. (LEITE, 2011, p. 43).

Este texto problematiza o currículo escolar como possibilidade de ações inventivas por meio da prática docente, entendendo, tal como na epígrafe, que o processo de formação de professores acontece por afetações, sensibilização, rupturas, criações, recriações, invenções, reinvenções. Nesse sentido, é necessário desviar das formações tradicionais com práticas e acontecimentos que potencializem afetos, afetações e possibilidades de profanar a padronização e o disciplinamento dos corpos no contexto escolar. Tais problematizações do currículo foram mobilizadas por professores atuantes em escolas básicas situadas na Amazônia brasileira. 
A questão central é: como fomos afetados pelos textos lidos e discutidos, pelo documentário "Escolarizando o Mundo: o último fardo do homem branco" e pelas falas dos colegas encharcadas de vivências plurais e situadas e pela mediação didática da professora?

O texto mobiliza experiências de profissionais da educação básica durante estudos e discussões realizados na disciplina "Inovações Curriculares e Didática"4, ministrada em um Programa de Pós-Graduação em Educação Escolar de uma universidade pública situada no Norte do Brasil, bem como os acontecimentos vivenciados pelos autores (um professor de matemática da rede estadual de educação, uma técnica em assuntos educacionais da rede federal de educação básica, técnica e tecnológica e uma professora universitária).

Entendemos, como Paraíso (2016), que é importante em nosso ato de professorar a construção de práticas inventivas, atos criativos de um currículo situado que nasce das vivências das escolas - vivências que afirmam as formas de vida, da diferença e da alegria. Compreendemos que a inovação, o currículo e a didática vão muito além do que está escrito, dos parâmetros nacionais institucionalizados em um determinado tempo da história, "porque em um currículo sempre há espaço para os encontros que escapam ao controle, que resistem e extrapolam ao planejado, que se abrem para a novidade" (PARAísO, 2016, p. 389). Basta olhar para a trajetória escolar, as vivências que proporcionamos aos nossos estudantes, cada palavra dita ou não dita, o que se passa ou não se passa, o olhar, o sentimento, o riso, a caminhada, o afeto, o pensamento, o silêncio, a conversa, o medo.

Nessa mesma direção,

\footnotetext{
${ }^{4}$ A disciplina "Inovações Curriculares e Didática" foi ministrada com a seguinte ementa: Concepções de currículo e seus desdobramentos relacionados à prática pedagógica no Ensino Fundamental. Interação dialógica entre escola e vida considerando o desenvolvimento humano, o conhecimento e a cultura. A escola como espaço e ambiente educativo para a ampliação da aprendizagem. Currículo e produção de conhecimento para a diversidade e inclusão como direito ao desenvolvimento pleno do ser humano. A disciplina teve como objetivo desenvolver a compreensão das políticas de formação inicial e continuada de professores, no âmbito dos aspectos sociais, políticos, culturais e econômicos implicados na história da profissão e na prática da docência.
} 
É preciso [...] sentir os sopros de vida que explodem nos corredores, recreios e conversas nas escolas. Pensamos nas sutilezas dos cotidianos como formas de linguagem que nos afetam e nos colocam em constante performance diante dos sopros que trazem consigo. Perseguidos pelas incertezas e emaranhados em experimentações, produção dos encontros entre corpos produzidos nos cotidianos das escolas que agenciam continuamente performances, entendidas como resistência e modos de agenciamentos nas relações curriculares (MELOTTI, 2019, p. 1).

Com este entendimento, levamos a questão da prática docente e do currículo escolar ao divã terapêutico, entendendo, como Miguel e Tamayo (2020), que o propósito de toda terapia, por um lado, é detectar e desconstruir imagens doentias, enrijecidas, cristalizadas, ilusórias, inadequadas ou improcedentes de um problema levado ao divã - e, por outro, mostrar panoramicamente outras imagens desses problemas vistas como adequadas. Cabe a nós, portanto, identificar e desconstruir imagens colonizadoras da educação escolar, mostrando outras imagens de se fazer escola.

Novamente com Miguel e Tamayo (2020), podemos dizer que ainda vivemos um novo colonialismo sem mais colônias, mas que persistiria no cheiro e nas cores das tintas com que se pintam as paredes escolares; nas bandeiras que se hasteiam nos mastros dos pátios das escolas; nas línguas e nos jogos de linguagem das escritas dos livros escolares; nas disciplinas, nos currículos e nas práticas escolares de todas as escolas republicanas nacionais e nacionalistas.

Nessa visão, a narrativa ficcional que compõe este artigo, em que os encadeamentos discursivos foram realizados por meio de citações e enxertias 5 , é baseada nas memórias e discussões ocorridas na sala de aula da educação básica, principalmente os textos sobre currículo e práticas docentes que vão ao encontro dos acontecimentos'b vivenciados pelos autores em seu fazeres educacionais em diferentes instituições educacionais.

\footnotetext{
5 A "prática da enxertia textual, esta opera através da inserção de um discurso em outro, bem como da intervenção no discurso que se está desconstruindo" (FARIAS, 2014, p. 12-3). 6 "Convém lembrar que um acontecimento supõe a surpresa, a exposição, o antecipável [...]" (DERRIDA, 2012, p. 231).
} 


\section{CENA 1: A GRANDE SACADA (PRIMEIRO ATO)}

CENÁRIO: O palco aqui se forma na lanchonete de uma universidade federal da região Norte do Brasil, durante um intervalo da disciplina "Inovações Curriculares e Didáticas" (lecionada na terceira semana de fevereiro de 2020), logo após o seminário apresentado pelos professores Magno e Eloá, que são os personagens desse ato.

PROFESSOR MAGNO (pensativo): - Sabe, Eloá, durante a semana dessa disciplina, em paralelo, estamos tendo na escola em que eu atuo uma formação a respeito da Base Nacional Comum Curricular (BNCC) para o ensino médio, que eles chamam de "ensino médio ampliado". As técnicas da SEDUC7 ${ }^{7}$ que ministraram o curso de formação foram bem na exposição das mudanças no currículo para o ensino médio, mas algo me deixou pensativo.

PROFESSORA ELOÁ (curiosa): - Conte-me mais sobre a formação.

PROFESSOR MAGNO (respirando fundo): - As técnicas estavam bem entusiasmadas durante o curso, mas após as várias discussões que estamos tendo ao longo desta disciplina, me questiono se essa nova base curricular vai mudar alguma coisa.

PROFESSORA ELOÁ (ansiosa): - Você tem razão, pois as vozes que ecoaram até agora na disciplina "Inovações Curriculares e Didática" apontam para algumas problematizações nas mobilizações das práticas docentes.

PROFESSOR MAGNO (em concordância): - "Problematizar", é assim que me encontro essa semana, problematizando algumas situações. Primeira causa disso foi aquele documentário a que assistimos, intitulado "Escolarizando o Mundo"8, que nos mostrou um outro lado dos projetos educacionais do Ocidente, que têm como promessa trazer uma vida melhor... Mas, no filme, foram expostas diversas falhas nesses modelos que são vendidos como os melhores, você deve ter notado.

\footnotetext{
7 Secretaria de Estado da Educação de Rondônia (SEDUC-RO).

8 Documentário disponível em: https://www.youtube.com/watch?v=6t_HN95-Urs. Acesso: 9 de maio 2020.
} 
PROFESSORA ELOÁ (afirmando com a cabeça): - Sim! O documentário foi muito provocativo! Entender o processo de escolarização na América, a função social da escola e a implementação de currículos... Deleuze (1968) afirma que o poder é um campo de forças e que a força se define por seu poder de afetar ou ser afetada. O documentário proposto pela Fada Azul sem dúvida alguma me afetou. Posso dizer ainda que provocou uma grande desconstrução, ao me possibilitar enxergar outra face do processo de escolarização e compreender que o currículo é um forte campo das relações de poder, que frequentemente é imposto visando potencializar os interesses do Estado por meio da educação escolarizada.

PROFESSOR MAGNO (em concordância): - A escola pode ser uma eficiente e silenciosa arma de dominação, promovendo mobilizações por meio da implantação de currículos opressores, silenciando vozes, extinguindo culturas, subjugando, humilhando, desvalorizando e convencendo povos inteiros que seus costumes e tradições não têm importância. Nesse sentido, "sem exagero, pode-se dizer que o currículo funcionou como o principal artefato escolar envolvido com a fabricação do sujeito moderno" (VEIGANETO, 2008, p. 47).

PROFESSORA ELOÁ (afirmando com a cabeça): - Sim! Impossível não notar. Pode parecer um ato de bondade educar dentro de certos modelos, afinal, educação é uma necessidade. Mas, como diz Paulo Freire, toda educação é política - e não existe neutralidade. No texto "A crise na educação" (incluído no livro Entre o passado e o futuro), Arendt apresenta, com a habitual veemência e coragem, uma visão bastante crítica do tipo de educação considerada "moderna", naquela época e hoje; ela escreve: "A educação é o ponto em que decidimos se amamos o mundo o bastante para assumirmos a responsabilidade por ele" (ARENDT, 1961, p. 221).

(Pequena pausa.)

É preciso ir à escola para ter vida em sociedade, é preciso seguir o currículo, ter uma formação; no entanto, a educação, que tanto almejamos ser libertadora e motor de mudanças sociais é também uma arma capaz de matar culturas inteiras. 
PROFESSOR MAGNO: - Muito bem lembrado, Eloá. E dentro dessa questão de que a educação "é também uma arma capaz de matar culturas inteiras", entra a segunda causa de minhas problematizações, após a leitura do artigo para o seminário, intitulado "Currículo para estrangeiros ou para hóspedes? Algumas contribuições de Jacques Derrida para 0 pensamento curricular", de Bonnie Axer (2012). Apesar de ser do ano de 2012, as reflexões críticas sobre o currículo feitas neste artigo ainda me pareceram bem atuais diante do que foi exposto na formação da BNCC na escola em que atuo.

PROFESSORA ELOÁ (concordando):- Apesar de não estar participando da formação, preciso concordar com você, pois é necessário buscar formas outras de pensar e construir o currículo.

PROFESSOR MAGNO (enfático): - Ora, pelo discurso das técnicas da SEDUC, fico com a impressão de que os definidores de currículo achavam em certo momento que currículo era somente uma grade de disciplina. Em outros momentos, elas davam a entender que eles pensavam que currículo era apenas um conjunto de expectativas de aprendizagem. Mas no decorrer dessa semana, vimos que currículo é um conceito muito mais amplo.

PROFESSORA ELOÁ (concordando): - Você tem razão! É preciso desconstruir, ver por outro ângulo e saber jogar as regras do jogo...

PROFESSOR MAGNO (corta): - Por isso Axer (2012) afirma que, ao falarmos de currículo, lembramos de grade curricular, ementas, planos de aula, seleção de conteúdo, entre outros. Mas nós ampliamos esse entendimento: "currículo é lugar, espaço, território, é relação de poder, é trajetória, é percurso, é viagem, é texto, é discurso, é documento, é documento de identidade" (SILVA, 2004 apud AXER, 2012, p. 214). Definindo de forma mais sucinta, acabamos por entender que o currículo é uma construção cultural.

PROFESSORA ELOÁ (pensativa): - É importante que a ação do currículo "respeite a diferença e singularidade de cada aluno" (AXER, 2012, p. 214). 
PROFESSOR MAGNO (problematizando): - O que sabemos que não acontece em nossas escolas. Axer (2012) exemplifica a situação com a chegada de um estrangeiro a um novo país, com a intenção de ali se fixar; ele tem que perder suas características de estrangeiro, renunciando ao seu mundo, para poder gozar de algum tipo de hospitalidade. Trazendo este exemplo para o âmbito escolar, conseguimos ver que o estrangeiro é o aluno e o novo país é a escola, e quando passamos a atuar como docentes, vemos essa situação quase que cotidianamente.

Posso até the dar um exemplo bem simples, que acontece muito dentro da área em que atuo. Nós nos deparamos com professores que fazem avaliações escritas e, caso o aluno resolva uma questão de forma diferente da que o docente explicou, ainda que haja toda uma lógica e a resposta esteja correta, o professor com frequência não a considera, pois quer que o aluno faça do modo como ele ensinou, mesmo que muitas vezes aquele não seja o método universal de resolução de determinada situação problema. Vivi essas situações até na universidade. Enquanto buscava minha formação, nós, acadêmicos, éramos os estrangeiros que não tínhamos o direito de trazer nada de nossas características de estrangeiros se quiséssemos a aprovação nas disciplinas; tínhamos que perder nossas identidades e desprezar toda a carga de vivências que trazíamos antes de ingressar no curso para agradar aos nossos professores.

Voltando ao assunto da formação, me lembrei de outro momento, quando alguns professores questionaram se os definidores de currículo pensaram que a realidade da cidade de Porto Velho era diferente, por exemplo, da realidade da cidade de São Paulo. Então, como é que um currículo do ensino médio igual em todo o país vai trazer alguma mudança?

PROFESSORA ELOÁ (enfática): - Provavelmente não traga mudanças significativas! Jamais vivenciamos as mesmas experiências.

PROFESSOR MAGNO (complementando): - A resposta das técnicas da SEDUC foi que, para isso, a BNCC para o ensino médio traz as disciplinas eletivas, que serão ministradas de acordo com a realidade de cada escola. Mas eu vejo que colocar mais disciplinas na grade do ensino médio acaba 
por tirar o espaço de outras sem nenhuma vantagem, afinal, para lecionar essas disciplinas eletivas, basta que o ministrante tenha "notório saber".

PROFESSORA ELOÁ (com um olhar apreensivo): - E, de algum modo, isso traz uma certa preocupação, pois:

\begin{abstract}
Falar de currículo atualmente é falar de um campo polissêmico, um múltiplo artefato apresentado e vivenciado não somente de forma engessada, ou visto apenas aos olhos de seleção de saberes, culturas ou conteúdos programados, mas fundamentalmente, como produção de conhecimento e sentidos (AXER, 2012, p. 216).
\end{abstract}

PROFESSOR MAGNO (suspirando fundo): - Exatamente, Eloá. Mas a impressão que fica é que os definidores de currículo vão tendo muitas ideias a respeito de expectativas de aprendizagem e disciplinas e se esquecem de duas coisas: a primeira é que o dia só tem 24 horas; a segunda é que não basta ter boas ideias, é preciso pensar em todo o contexto.

PROFESSORA ELOÁ (complementando): - As ideias até podem ser boas, porém, fogem do ideal. É preciso nascer um desejo de fazer diferente, um desejo de desconstrução:

com este desejo de desconstruir, penso as produções curriculares enquanto textos coletivos, que pensados e produzidos em contextos institucionais, sendo assim impossível, a meu ver, pensar em um único endereçamento dos mesmos até em uma projeção de um único sujeito ideal (AXER, 2012, p. 226).

PROFESSOR MAGNO (tentando interpretar o olhar de Eloá): - Bom, agora, acho que você pode estar questionando em pensamento o motivo de tantas problematizações que geraram essa nossa pequena discussão durante o intervalo.

PROFESSORA ELOÁ (sorrindo): - E como foi que você acertou? Essa era a dúvida que pairava em meus pensamentos.

PROFESSOR MAGNO (relembrando): - Eu li boa parte das propostas da BNCC para a matemática do ensino médio, participei de todo o curso de formação e tudo isso me remeteu a um acontecimento de meses atrás, quando uma aluna me questionou se na graduação em psicologia "tinha 
matemática". Acabei percebendo, com essas nossas experiências ao longo da semana, que o currículo para o ensino fundamental a levou a não gostar da disciplina de matemática num nível que ela quer fazer uma graduação que não tenha nenhuma disciplina associada à matemática. E esse tipo de pensamento me assusta, apesar de ser mais comum do que nós imaginamos.

Atualmente, essa aluna se encontra no $1^{\circ}$ ano do ensino médio, este que já estará de acordo com as novas diretrizes do ensino médio ampliado da BNCC. Mas me questiono se esse currículo estará pronto para receber essa aluna e, talvez, mudar a concepção que ela me apresentou no ano passado. Agora, eu Ihe faço um questionamento, Eloá: você gostava de matemática durante a escola, ou também tinha o mesmo pensamento que essa aluna?

PROFESSORA ELOÁ (trazendo recordações à memória): - Matemática sempre foi aquela disciplina temida por quase todos. Nunca fui de gostar dos números, ainda mais porque cresci ouvindo que a área das exatas era para os meninos. Além disso, sempre ouvia minha mãe contar que desistiu de estudar por causa da temida matemática. Isso mesmo que você está ouvindo! Minha mãe parou de estudar na quarta série primária por não gostar de matemática. E comigo não seria diferente. Nunca gostei de matemática!

Quando terminei o ensino fundamental, fui fazer o ensino médio técnico em processamentos de dados, por ser, na época, uma opção de emprego garantido para recém-formados. Fazer o curso foi um desafio enorme, pois a maioria das disciplinas envolvia cálculo. Dessa forma, como nunca fui de desistir de nada, terminei o curso na marra e fui fazer o magistério, uma boa opção para quem queria sair do curso com um emprego garantido. E para afirmar ainda mais a minha briga com a matemática, cursei a graduação em pedagogia.

PROFESSOR MAGNO: - Fico muito triste com esse tipo de relato, porque a disciplina que leciono acaba por se tornar uma disciplina excludente. Talvez um dos motivos que tenham levado sua mãe a desistir de estudar por 
causa da matemática seja o que Miguel (2016) define como "matemática escolar", que, na verdade, é um amontoado de conceitos e regras totalmente dispensáveis para entendermos os problemas do mundo à nossa volta, e seu currículo é organizado em uma lista de conteúdos "conceituais, genéricos, abstratos, desconectados das práticas culturais e campos extraescolares de atividade" (MIGUEL, 2016, p. 351).

(Fim do primeiro ato.)

\section{CENA 2: (IM)POSSÍVEL FUGA DA MATEMÁTICA (SEGUNDO ATO)}

E isto representaria uma fuga imperdoável, ao destino simplesmente humano, que é feito de luta e sofrimento e perplexidade e alegrias menores. (LISPECTOR, 2013, p. 56).

CENÁRIO: O palco é formado pela sala de aula de uma escola pública da rede estadual de educação. O momento é o final de uma aula de matemática numa turma do $9^{\circ}$ ano; os personagens ficcionais deste ato são o professor Magno e a aluna Érica. É uma manhã de sol e o conteúdo trabalhado é a simplificação de radicais. A aula chega ao final e, enquanto o professor Magno arruma seu material espalhado por cima da mesa para seguir à sua próxima sala, a aluna Érica chega à mesa do professor e, sem rodeios, Ihe faz o seguinte questionamento:

ÉRICA (inquieta): - Professor, na graduação em psicologia a gente estuda matemática?

(O professor é pego de surpresa com aquela pergunta; afinal, questionamentos sobre graduação vindos de turmas do ensino fundamental não são comuns, e perguntas como aquela, até o presente momento, jamais lhe tinham sido feitas. O professor, no entanto, em seguida lhe dá uma resposta.)

PROFESSOR MAGNO (prestativo): - Olha, vou pesquisar e amanhã the trago a resposta. Pode ser?

ÉRICA (balançando a cabeça): - Certo, professor. 
(No dia seguinte, após o término de mais uma aula, o professor Magno chama a aluna Érica para responder ao questionamento do dia anterior.)

PROFESSOR MAGNO: - Érica, por favor.

ÉRICA: - Sim, professor.

PROFESSOR MAGNO: - Dei uma rápida pesquisada na grade curricular em vigência do curso de psicologia da Universidade Federal de Rondônia, e vi que existe uma disciplina chamada "Estatística Aplicada à Psicologia".

ÉRICA (faz cara de tristeza): - Poxa, professor, eu queria fazer psicologia por achar que não estudaria matemática.

PROFESSOR MAGNO (com um sorriso): - Érica, existem duas coisas das quais você não pode escapar nessa vida, da morte e da matemática.

ÉRICA (enfática): - Eu não gosto de matemática, professor!

PROFESSOR MAGNO: - Mas que motivos te levam a não gostar da matemática?

ÉRICA: - Vejo a matemática como uma disciplina muito confusa e que não tem nada a ver com a minha vida.

PROFESSOR MAGNO: - Talvez um dos motivos para essa sua opinião seja devido a um erro muito recorrente quando se fala em "educação matemática", que consiste em desvincular a matemática das nossas práticas humanas e culturais. A matemática está presente em todas as civilizações, auxiliando a humanidade a criar estratégias para conseguir lidar com o ambiente e buscando dar explicações acerca dos fenômenos da natureza, ou seja, "em todos os momentos da história e em todas as civilizações, as ideias matemáticas estão presentes em todas as formas de fazer e de saber" (D'AMBROSIO, 1999, p. 97).

ÉRICA: - Mas professor, sinto que tudo que estudamos, além de ser muito difícil, não me serve para nada. Sendo bem honesta com o senhor, eu odeio matemática.

PROFESSOR MAGNO: - Essa aversão que você tem pela matemática pode ser decorrente da forma disciplinar como ela é apresentada na escola.

ÉRICA: - Forma disciplinar? 
PROFESSOR MAGNO: - O regime disciplinar é uma forma de modificar a cultura de indivíduos que vem sendo utilizado desde o século XIX por escolas e universidades. Em resumo, esse regime promete preparar vocês, alunos, para a convivência em sociedade e no trabalho, mas claramente ele falha em dar essa formação, causando inclusive a exclusão de pessoas desse processo. Ou seja, "tal princípio falha também em formar cidadãos e nem contribui para a democratização social, política e econômica de um estado-nação" (MIGUEL; VILELA; MOURA, 2012, p. 8).

ÉRICA: - Professor, não vou negar que me sinto excluída mesmo na disciplina de matemática, me sinto "burra" demais.

PROFESSOR MAGNO (corta): - Não precisa utilizar esse termo, você não é "burra". O que acontece é que a matemática escolar muitas vezes não dialoga com as práticas e os problemas do mundo social.

\begin{abstract}
A breve olhada para as diferenças entre a aritmética da rua e a escolar sugere que cada uma delas envolve seus próprios significados e suas próprias maneiras de proceder e avaliar os resultados desses procedimentos, e sugere que essas diferenças acabam constituindo legitimidades, pois do mesmo modo que a escola proíbe os métodos da rua - em geral chamados de informais, e dizendo que são de mobilizações limitadas -, a rua proíbe os métodos da escola, chamando-os de complicados e sem significados, e dizendo que não são necessários na rua (MIGUEL; VILELA, 2008, p. 111).
\end{abstract}

ÉRICA: - Concordo. Eu sinto que muito do que eu estudo de matemática em sala de aula não vai servir em nada na minha vida, que tudo vai ficar aqui na escola, sem condições de resolver questões da vida cotidiana.

PROFESSOR MAGNO: - ISSO é o que muitos historiadores acusam que acontece ao longo da história. Existe um diálogo controverso entre as ciências da natureza e o conjunto de saberes que é denominado matemática. Talvez seja por esse motivo que, "desde a produção dos primeiros programas escolares da disciplina matemática, em nosso país, tem sido natural vê-la exclusivamente como uma coadjuvante do ensino das 
denominadas ciências da natureza, dentre elas, sobretudo, a Física" (MIGUEL, 2016, p. 330).

Mesmo após as políticas educacionais da Nova República, a matemática ainda continua dialogando de forma tímida com os demais campos, e muitas vezes esses diálogos, quando acontecem dentro da educação escolar, são feitos de forma forçada e artificial, fazendo com que a matemática seja vista como um campo autônomo em relação aos demais campos. E ainda temos outro empecilho, que é o nosso currículo de formação de professores, em que

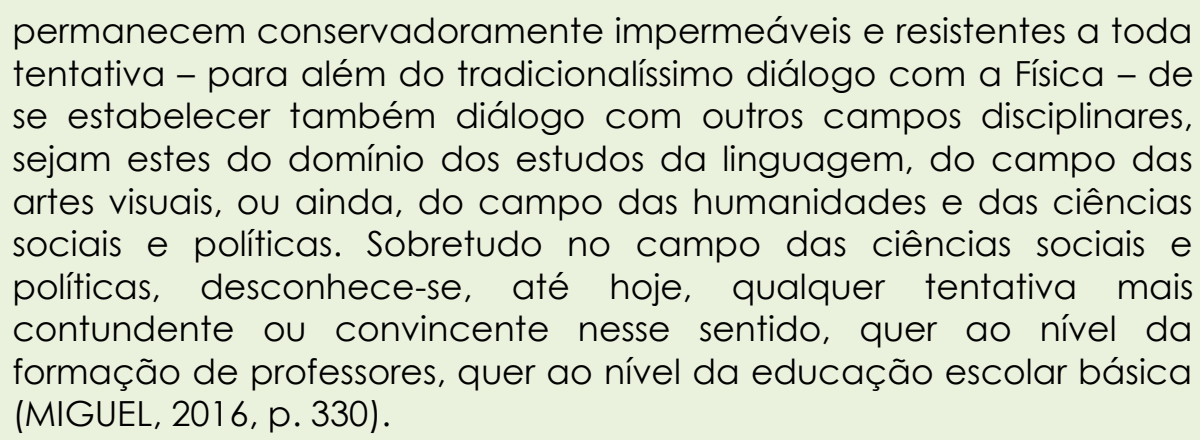

ÉRICA: - Mas, então, como poderia ocorrer esse diálogo da matemática com outros campos?

PROFESSOR MAGNO: - Veja, o regime trabalhado em nossas escolas é o disciplinar. Seria ideal que ele fosse substituído por um que não fosse pautado nessas noções de disciplinas e na clássica forma de conteúdo.

ÉRICA: - Então, teríamos que ter um novo regime?

PROFESSOR MAGNO: - Sim, um regime chamado indisciplinar de mobilização cultural, no qual a matemática, "uma vez desconstruída como disciplina escolar, seja inscrita, juntamente com as demais disciplinas escolares igualmente desconstruídas, numa política curricular indisciplinar de mobilização cultural" (MIGUEL, 2016, p. 336). Devemos lutar por uma democratização das práticas escolares, abrir a escola para as mais diversas formas institucionais de vida pública, ou seja, para a ampliação do campo dialógico problematizador da escola com a finalidade de abordar todos os 
campos de atividades humanas, e não ficar restrito somente ao campo acadêmico-científico de atividade.

\begin{abstract}
A passagem do regime disciplinar para o indisciplinar deve expressar, portanto, esta necessidade de abertura democrática do campo dialógico da escola. E, portanto, tal passagem só pode consistir na incorporação à cultura escolar de todas as práticas culturais extraescolares, de modo que as próprias práticas científicas disciplinares percam o seu estatuto epistemológico privilegiado e, desconstruídas, também passem a ser vistas como práticas culturais ou, o que dá no mesmo, como jogos de linguagem. (MIGUEL, 2016, p. 356).
\end{abstract}

Quando dizemos que precisamos desconstruir a matemática enquanto disciplina escolar, isso significa que ela, assim como as demais disciplinas, deve ter um novo significado. Podemos fazer isso através de jogos de linguagem.

ÉRICA: - Como assim, jogos de linguagem?

PROFESSOR MAGNO - Para Wittgenstein, um jogo de linguagem é "um jogo situado de performance corporal dos jogadores que, nele, interagem entre em si" (MIGUEL, 2016, p. 332). Com relação à matemática, esses jogos de linguagem também são encenações corporais realizadas em espaço e tempo definidos, e não modelos abstratos, estáticos e genéricos de outros jogos de linguagem.

ÉRICA: - Aprender jogando... Seria tipo como aprender jogando futebol?

PROFESSOR MAGNO: - Sim, isso mesmo. É quando aprendemos a fazer algo novo com o corpo de acordo com as regras que são definidas, isso, é claro, se o jogo tiver regras definidas. Tudo aquilo novo que aprendemos pode ser considerado uma prática cultural. Além desse exemplo de jogar futebol que você deu, também podemos elencar outras coisas, como cozinhar, costurar uma roupa, recitar um poema, provar um teorema, entre outras. Também não posso deixar de destacar que, na perspectiva wittgensteiniana, não existe aprendizagem criativa ou repetitiva sem que o aprendiz tenha participado de um jogo de linguagem. A condição para a aprendizagem é participar dos jogos de linguagem, ou seja, "pode-se, 
então, dizer que aprender é aprender a jogar e que só se pode aprender a jogar jogando. É assumir uma posição no jogo, junto aos demais jogadores, e agir em conformidade a regras definidas para aquela posição" (MIGUEL, 2016, p. 347).

ÉRICA: - Nossa, acho que com isso passo a me sentir menos culpada. Sempre colocava a culpa em mim mesma por ter essa dificuldade em conseguir entender a matemática.

PROFESSOR MAGNO (retomando): - Então, é bem difícil você achar algum curso de graduação que não tenha matemática. Mas se você quer realmente cursar psicologia, vá em frente, afinal, é só uma disciplina e você vai sobreviver.

ÉRICA (um pouco mais satisfeita): - Está bem, professor, muito obrigada!

(Fim do segudo ato.)

CENA 3: A SAGA EM BUSCA DE NOVOS SABERES (TERCEIRO ATO)

O acontecimento fica tatuado [...]. (LISPECTOR, 1999, p. 22).

Estamos presos em nossa pele. (GEBAUER, 2013, p. 199).

CENÁRIO: O palco se forma após o término da última aula da disciplina "Inovações Curriculares e Didáticas", mais especificamente no corredor da universidade rumo ao estacionamento; os personagens deste terceiro e último ato, mais uma vez, são os professores Magno e Eloá.

PROFESSORA EloÁ (pensativa): - Sabe, Magno, percebo que ao compartilhar os acontecimentos vivenciados por você, tanto em sala de aula quanto na formação, foi possível reconhecer neles inquietações quanto ao fazer docente. Fico me perguntando: de que maneira podemos afetar esse aluno para que o acontecido com a minha mãe ou o questionamento feito pela aluna Érica não sejam recorrentes? 
PROFESSOR MAGNO (inquieto): - E eu ainda faço outra pergunta. O que nós precisamos fazer com o nosso aluno ao dar aula? Algo precisa ser feito.

PROFESSORA ELOÁ (radiante): - IsSO me fez lembrar da fala da professora (nossa Fada Azul)9 ao ministrar a disciplina, que é preciso proporcionar um encontro com nossos alunos, e esse encontro tem que gerar um acontecimento. Eu não posso apagar tão facilmente uma tatuagem, pois ela rompe a pele, rompe os músculos. Dessa forma, temos que marcar a vida dos nossos alunos como uma tatuagem; eles ficam marcados com a nossa presença e a presença do outro.

PROFESSOR MAGNO (suspirando fundo): - "O acontecimento é também o que vem, o que chega" (DERRIDA, 2012, p. 233). Pensando junto com Derrida, posso afirmar que a fala da Fada Azul faz sentido, pois "dizer o acontecimento é também dizer o que chega e tentar dizer o que é presentemente e se passa presentemente, logo dizer o que é, o que vem, o que chega, o que se passa" (DERRIDA, 2012, p. 235).

PROFESSORA ELOÁ (com a voz animada): - Sabe, Magno, a nossa aula nada mais é do que um encontro, um encontro de pessoas, e todo encontro gera um acontecimento; "quando eu acolho um visitante, a visitação de um visitante inesperado, isso deve ser cada vez uma experiência única para que isso seja um acontecimento, único, imprevisível, singular, insubstituível" (DERRIDA, 2012, p. 243).

PROFESSOR MAGNO (concordando com a cabeça): - Então podemos dizer que isso gera no nosso aluno uma desconstrução e uma reconstrução novamente, pois esse é o nosso papel de professor, fazer a didática acontecer.

PROFESSORA ELOÁ (acrescentando): - O nosso papel de professor, essa didática, essa inovação curricular, é trazer o que está posto como norma, o que está escrito como obra morta e transformar em uma obra viva capaz de gerar um olhar diferente.

\footnotetext{
${ }^{9}$ Nome fictício da professora que ministrou a disciplina "Inovações Curriculares e Didática".
} 
[...] trazer algo novo, uma leitura ainda não feita ou desta forma ainda não dita ao mesmo tempo em que traz também a releitura e o reposicionamento de algo que não foi suficiente em um dado momento, mas que colocado de outra forma, dialogado com outras visões se faz importante para aquilo que queremos defender. (AXER, 2012, p. 215).

PROFESSOR MAGNO (com olhar interrogativo): - E como posso transformar essa obra morta em uma obra viva?

PROFESSORA ELOÁ (entusiasmada): - No encontro com o outro, no falar, no dizer, no olhar, no sentir do outro. Dessa forma, transformamos a aula em um acontecimento que ninguém vai querer perder. Ninguém vai querer perder esse encontro.

PROFESSOR MAGNO (concordando com a cabeça): - Eu acredito nisso, que ainda há esperança de fazer uma educação diferente, de fazer nosso aluno pensar diferente, seja em relação à matemática, seja em relação a outra disciplina.

PROFESSORA ELOÁ (com um semblante positivo): - E fará sentido quando estivermos com essa visão da aula como um encontro, do que a gente pode fazer no outro em termos de acontecimentos. Com a aula, podemos fazer o nosso aluno se apaixonar pela matemática e pela escola, sendo esta "um local privilegiado de troca de ideias, de encontros, de legitimação de práticas sociais, de interação entre diferentes gerações, além de articulação de padrões culturais" (AXER, 2012, p. 215).

PROFESSOR MAGNO (acrescentando): - O professor deve ser capaz de criar situações novas, momentos de um encontro de corpus significativo para a formação desse aluno. Se o professor quiser, ele pode, sim, fazer viver o que está posto.

PROFESSORA ELOÁ (pensativa): - A inovação, o currículo e a didática vão muito além do que está escrito. É só olhar para a trajetória escolar, as vivências que proporcionamos aos nossos alunos, cada palavra dita ou não dita, o que se passa ou não se passa, o olhar, o sentimento, o riso, a caminhada, o afeto, o pensamento, o silêncio, a conversa, o medo... 
PROFESSOR MAGNO (complementando): - Exatamente, Eloá! A escola é determinante para pensarmos como nós pensamos, para nos constituir enquanto pessoas capazes de transformar uma aula em um encontro de corpus e fazer esse encontro gerar um acontecimento.

(Fim do terceiro ato.)

\section{RASTREANDO MEMÓRIAS POR MEIO DE JOGOS DE LINGUAGENS}

As memórias de um acontecimento serão praticadas por meio de jogos de linguagem ${ }^{10}$. Para Wittgenstein, a linguagem expressa o real em suas funções práticas, no uso que se faz da palavra. As palavras não dão apenas nomes às coisas: são significadas nos jogos de linguagem, na ação prática influenciada por aspectos sociais, culturais e históricos - "assim são diferentes as funções das palavras" (WITTGENSTEIN, 1999, p. 31) -, e o significado de uma palavra é o seu uso na linguagem, dependendo da forma de vida em que esta se situa. Nesse sentido,

pode-se representar facilmente uma linguagem que consiste apenas de comandos e informações durante uma batalha. - Ou uma linguagem que consiste apenas de perguntas e de uma expressão de afirmação e de negação. E muitas outras. - E representar uma linguagem significa representar-se uma forma de vida. (WITTGENSTEIN, 1999, p. 32).

Os debates no contexto das práticas matemáticas na educação escolar pautados no pensamento filosófico de Wittgenstein, segundo Miguel, Vilela e Moura (2012), têm o intuito de ampliar nosso modo de compreensão para além de um único e privilegiado. Ao descrever a utilização de vários olhares, "Olhar como se designam as coisas em diferentes situações na prática da linguagem, olhar para suas diferentes aplicações, efetivas, possíveis, [...], tal como fez Wittgenstein nas Investigações é denominada terapia" (MIGUEL; VILELA; MOURA, 2012, p. 10). Os autores completam que a terapia tem como intuito desfazer as imagens privilegiadas de uma única e exclusiva prática. Essas imagens exclusivas, que podem parecer eternas e linguagem e pelas atividades com as quais ela vem entrelaçada" (FARIAS, 2014, p. 50). 
não podem ser realizadas de outra maneira, são consideradas por Wittgenstein como uma "doença filosófica", pois alimentam os pensamentos apenas com base em um único exemplo.

A desconstrução decorre justamente do fato de os enunciados serem disponíveis para citação, por conta da iterabilidade, repetibilidade e citacionalidade da linguagem; porém, "aquilo que é desconstrução diz respeito, vem de, retira de, ou é, de um certo modo, de construção" (MENESES, 2013, p. 202). Logo, é uma estratégia de pensar diferente, na qual é possível transformar realidades em jogos performáticos. Dessa forma, a linguagem pode assumir diversas "performances".

Na performance da escrita [...], entendemos que os textos diferem e ditam suas próprias leituras e que nenhum contexto exclui outros contextos. Um texto não pode ser entendido como um conjunto de posições homogêneas, pelo contrário, é sempre heterogêneo. Há sempre possibilidades de encontrarmos, no texto estudado, algo a questionar e até mesmo a desconstruir, tal como defende Derrida. (FARIAS, 2014, p. 243).

Com base na visão dos jogos de linguagem/cenas, é possível transformar realidades em jogos performáticos utilizando a estratégia de ver por outro ângulo, dando significação a outros textos e contextos, utilizandose das "brechas/fendas" do (im)previsível. Para Derrida,

a fenda é necessária ao pensamento. Ela ocorre como um lugar e como uma possibilidade de um entre, em si mesma intransponível, ela, no entanto, abre-se, em um discurso, em uma instituição, em culturas e políticas, a fim de dar lugar à possibilidade de uma outra ocorrência, o evento sem precedentes pelo qual a transformação, a tradução e a interpretação têm suas chances. (WOLFREYS, 2009, p. 32).

Seguindo a linha teórico-metodológica do movimento pós-virada linguística e decolonial, com base na filosofia de Ludwig Wittgenstein e Jacques Derrida, Marim e Farias (2007) nos trazem uma compreensão sobre atos narrativos em textos científico-acadêmicos a partir da encenação corporal de práticas culturais na escrita e na fala (verbais ou não). Temos então um estilo de escrita que vem ganhando espaço entre os textos 
científico-acadêmicos, intitulado "escrita dialógica" - também conhecido como "jogos de cenas".

Os jogos de cenas possuem uma ideia de performance através da linguagem sob uma estrutura filosófica pragmática e não essencialista. Segundo Marim e Farias (2017), eles se mostram "como constituição nas (im)possíveis dobras do fazer acadêmico e do narrar, sobretudo, no campo da historiografia em Educação (Matemática)" (MARIM; FARIAS, 2017, p. 176). Os jogos de cenas na narração de textos científico-acadêmicos vêm sendo utilizados em diversos trabalhos do grupo PHALA 11, da Faculdade de Educação da Universidade Estadual de Campinas (Unicamp), os quais:

remetem aos estudos da Teoria dos Atos de Fala de John L. Austin (1911 - 1960) e John R. Searle (1932), na área da filosofia da linguagem, postulando $\mathrm{o}$ entendimento da linguagem enquanto performance (MCDONALD, 1994; 2001), erguidos sob o arcabouço da filosofia analítico-pragmática de Ludwig Wittgenstein e da filosofia analítico-desconstrucionista de Jacques Derrida. (MARIM; FARIAS, 2017, p. 176).

A forma de utilização dos jogos de cenas nos textos científicoacadêmicos é sustentada no que Marim e Farias (2017) chamam de "compreensão abrangente da narratividade", bem próximo da noção de ato narrativo ou encenação narrativa. Partindo dessa perspectiva, foi possível narrar o diálogo entre o acontecimento vivenciado e a teoria, pois entendemos que, ao optar por um texto narrativo, estamos trazendo memórias de acontecimentos através de uma história contada.

Nesse sentido, os jogos de cenas nem são reais e nem ficcionais, pois eles têm ocorrência efetiva a partir de eventos efetivos, de documentos pesquisados, entrevistas realizadas, dentre outras ocorrências que constituem o ato de pesquisar. E se quisermos não nos deixar prender em dicotomias, como nos sugere o movimento derridiano da desconstrução, ou não nos deixar enfeitiçar pela linguagem, como nos diz Wittgenstein, não empreenderemos esforços para a pergunta "o que é jogos de cenas?", mas "como

11 Grupo de Estudos e Pesquisas em Educação, Linguagem e Práticas Socioculturais, composto por pesquisadores que problematizam a linguagem e as práticas culturais com interesse nos desdobramentos da virada linguística de diferentes instituições do Brasil. Site do grupo disponível em: https://www.phala.fe.unicamp.br/. 
são vistos?", ou "como são usados?" ou, ainda, "quais os efeitos que eles provocam?". (MARIM; FARIAS, 2017, p. 179).

Para tanto, o acontecimento foi narrado em três partes por personagens identificados de forma fictícia, e cada parte constitui uma encenação. Primeiro e terceiro atos são compostos pelo diálogo de dois alunos de mestrado inspirados pelos textos estudados na disciplina atrelados ao acontecimento narrado no primeiro ato, voltado à discussão da possibilidade de um fazer, um pensar e um olhar diferente. O segundo ato trata da fuga da matemática e das mobilizações de saberes e práticas em sala de aula, buscando desconstruir os olhares para a temática em questão.

O relato não tem o propósito de mostrar como aconteceram os estudos dos textos da disciplina, nem de apenas narrar o acontecimento vivenciado por um dos autores no seu fazer docente, mas problematizar as memórias de um acontecimento por meio dos afetos proporcionados pelas vozes que ecoaram durante a disciplina ministrada.

\section{ALGUMAS CONSIDERAÇÕES}

O texto tem como objetivo problematizar práticas curriculares e o fazer docente com base em estudos realizados na disciplina "Inovações Curriculares e Didáticas" dentro da linha de pesquisa Práticas Pedagógicas, Inovações Curriculares e Tecnológicas ${ }^{12}$, ministrada em um Programa de PósGraduação em Educação Escolar de uma universidade federal do Norte do Brasil.

Neste propósito, a relação entre os acontecimentos vivenciados e os textos estudados na disciplina contribuiu para mobilizações, desconstruções, significações e (re)significações dos saberes e práticas do fazer docente.

\footnotetext{
12 Realiza pesquisas que contribuem para a melhoria e o desenvolvimento das práticas pedagógicas escolares nas diversas áreas do conhecimento e em seus diversos tempos e espaços educativos, nas diferentes etapas e modalidades da educação básica, considerando as relações sociais para a produção subjetiva e material, a diversidade cultural e as necessidades de aprendizagens dos alunos. Propõe alternativas pedagógicas e tecnológicas inovadoras e de currículos e programas que contemplem a diversidade dos saberes na perspectiva intercultural e crítica para a transformação das escolas, da universidade e da sociedade. Investiga e analisa a formação inicial e continuada de professores e os processos de gestão desenvolvidos nos sistemas educacionais e seus impactos para a melhoria da qualidade da educação básica.
} 
Os jogos de cenas ficcionais expressaram nossas mobilizações na forma de encenação corporal de nossas práticas culturais no modo terapêutico, com base nos jogos de linguagem de Ludwing Wittgenstein e na desconstrução de Jacques Derrida. Com isso, foi possível realizarmos narrativas de fatos cuja performance decorreu dos acontecimentos vivenciados, narrados, interpretados, revividos, significados e experienciados.

Os diálogos apontaram para o fato de que não há uma receita pronta para a inovação curricular e a didática, mas há a possibilidade de reinventarmos coletivamente a escola, a sala de aula e o currículo; a possibilidade de fazer da aula um encontro e, desse encontro, um acontecimento; a possibilidade de fazer desse acontecimento uma experiência, e de problematizar as memórias de um acontecimento por meio dos afetos proporcionados pelos encontros trilhados nos rastros dos rastros que vão ao encontro de outros rastros.

\section{REFERÊNCIAS}

ARENDT, H. A crise na educação. Entre o passado e o futuro. São Paulo: Perspectiva, 1961. p. 221-47.

AXER, B. Currículo para estrangeiros ou para hóspedes? Algumas contribuições de Jacques Derrida para o pensamento curricular. Revista eCurriculum, São Paulo, v. 10, n. 3, dez. 2012. Disponível em: https://revistas.pucsp.br/curriculum/article/view/7968. Acesso em: 11 maio 2020.

D'AMBROSIO, U. A história da matemática: questões historiográficas e políticas e reflexos na educação matemática. In: BICUDO, Maria A. V. (org.).

Pesquisa em Educação Matemática: Concepções \& Perspectivas. São Paulo: Editora Unesp, 1999. p. 97-115.

DERRIDA, J. A escritura e a diferença. São Paulo: Perspectiva, 1971.

DERRIDA, J. Uma certa possibilidade impossível de dizer o acontecimento.

Revista Cerrados, v. 21, n. 33, p. 229-51, set. 2012. Disponível em: https://periodicos.unb.br/index.php/cerrados/article/view/26148. Acesso em: 9 maio 2020.

ESCOLARIZANDO o mundo: o último fardo do homem branco. (Título original: Schooling the world: the white man's last burden). Direção: Carol Black. EUA, 
Índia: Losł People Films, 2011.1 vídeo (66 min.). Disponível em:

https://www.youtube.com/watch?v=6t_HN95-Urs. Acesso em: 9 maio 2020.

FARIAS, K. S. C. S. Práticas mobilizadoras de cultura aritmética na formação de professores da Escola Normal da Província do Rio de Janeiro (1868-1889): ouvindo fantasmas imperiais. 2014. 405 p. Tese (Doutorado em Educação) Faculdade de Educação - Universidade Estadual de Campinas, Campinas, 2014.

GEBAUER, G. O pensamento antropológico de Wittgenstein. São Paulo: Loyola, 2013.

LARROSA, J. Notas sobre a experiência e o saber de experiência. Trad. João Wanderley Geraldi. Revista Brasileira de Educação, n. 19, p. 22-8, 2002.

Disponível em:

https://www.scielo.br/j/rbedu/a/Ycc5QDzZKcYVspCNspZVDxC/?lang=pt\&for mat=pdf. Acesso em: 9 maio 2020.

LEITE, C. D. P. Infância, experiência e tempo. São Paulo: Cultura Acadêmica, 2011.

LISPECTOR, C. A hora da estrela. Rio de Janeiro: Rocco, 1999.

LISPECTOR, C. Aprendendo a viver. Rio de Janeiro: Rocco, 2013

MARIM, M. M. B.; FARIAS, K. S. C. S. Traços vivos: jogos de cenas nas (im)possíveis dobras da escrita na pesquisa em educação (Matemática). Revista Exitus, Santarém/PA, v. 7, n. 2, p. 173-90, maio-ago. 2017. Disponível em:

https://www.ufopa.edu.br/portaldeperiodicos/index.php/revistaexitus/article /view/306/254. Acesso em: 9 maio 2020.

MELOTTI, A. C. J. Performances cotidianas como micropolítica de (re) invenção de vidas nas escolas. In: REUNIÃO NACIONAL DA ANPED, 39, 2019, Niterói. GT 12 - Currículo. Anais [...]. ANPED: Rio de Janeiro, 2019.

MENESES, R. D. B. A desconstrução em Jacques Derrida: O que é e o que não é pela estratégia. Universitas Philosophica, Bogotá, v. 30, n. 60, p. 177- 204, 2013. Disponível em:

http://www.scielo.org.co/pdf/unph/v30n60/v30n60a09.pdf. Acesso em: $1^{\circ}$ mar. 2019.

MIGUEL, A. Entre jogos e luzes e de sombras: uma agenda contemporânea para a educação matemática brasileira. Perspectivas da Educação Matemática. Revista do Programa de Pós-Graduação em Educação Matemática da UFMS, v. 9, n. 20, 2016. Disponível em: 
https://periodicos.ufms.br/index.php/pedmat/article/view/2877/2251. Acesso em: 15 fev. 2020.

MIGUEL, A.; TAMAYO, C. Wittgenstein, Terapia e Educação Escolar

Decolonial. Educação \& Realidade, Porto Alegre, v. 45, n. 3, e107911, 2020.

Disponível em:

https://www.scielo.br/j/edreal/a/Dr9NNdnXMHChBfYvVRdXrVf/?lang=pt.

Acesso em: 15 fev. 2020.

MIGUEL, A.; VILELA, D. S. Práticas escolares de mobilização de cultura matemática. Cad. Cedes, Campinas, v. 28, n. 74, p. 97-2010, jan./abr. 2008. Disponível em:

https://www.scielo.br/j/ccedes/a/S9BNCCb4HykNxbJPb5qfBmz/?lang=pt\&for mat=pdf. Acesso em: 19 de setembro de 2019.

MIGUEL, A.; VILELA, D. S.; MOURA, A. R. L. Problematização indisciplinar de uma prática cultural numa perspectiva wittgensteiniana. Revista Reflexão e Ação, Santa Cruz do Sul, v. 20, n. 2, p. 6-31, jul./dez. 2012. Disponível em: https://online.unisc.br/seer/index.php/reflex/article/view/3053. Acesso em: 15 fe. 2020.

PARAÍSO, M. A. A ciranda do currículo com gênero, poder e resistência.

Currículo sem Fronteiras, v. 16, n. 3, p. 388-415, set./dez. 2016. Disponível em:

http://www.curriculosemfronteiras.org/voll biss3articles/paraiso.pdf. Acesso em: 10 set. 2021.

VEIGA-NETO, A. Crise da modernidade e inovações curriculares: da disciplina para o controle. ANAIS. XIV ENDIPE- Encontro Nacional de Didática e Prática de Ensino, 2008. 27 a 30 de Abril, p. 335 a 58.

WITTGENSTEIN, L. Investigações filosóficas. Trad. José Carlos Bruni. São Paulo: Abril Cultural, 1999. (Coleção Os pensadores).

WOLFREYS, J. Compreender Derrida. Trad. Cesar Souza. 2. ed. Petrópolis: Vozes, 2009.

Recebido em: 05 de outubro de 2021. Aprovado em: 03 de novembro de 2021. Publicado em: 05 de novembro de 2021. 